\title{
Mitochondrial Phylogeny of Trematomid Fishes (Nototheniidae, Perciformes) and the Evolution of Antarctic Fish
}

\author{
Peter A. Ritchie, $\uparrow, *, 1,2$ Luca Bargelloni, $* \neq$ Axel Meyer, $*$, John A. Taylor, $\dagger$ John A. Macdonald, $\dagger$ \\ AND DAVID M. LAMBERT†,2 \\ †School of Biological Sciences, University of Auckland, Private Bag 92019, Auckland, New Zealand; * Department of Ecology and \\ Evolution and § Program in Genetics, State University of New York, Stony Brook, New York 11794-5245; \\ and ¥Dipartimento di Biologia, Universitá di Padova, Via Trieste 75, 35121 Padua, Italy
}

Received November 22, 1994; revised June 2, 1995

The subfamily of fishes Trematominae is endemic to the subzero waters of Antarctica and is part of the larger notothenioid radiation. Partial mitochondrial sequences from the 125 and 165 ribosomal RNA (rR NA) genes and a phylogeny for $\mathbf{1 0}$ trematomid species are presented. As has been previously suggested, two taxa, Trematomus scotti and T. newnesi, do not appear to be part of the main trematomid radiation. The genus $\mathrm{Pa}$ gothenia is nested within the genus Trematomus and has evolved a unique cyropelagic existence, an association with pack ice. Using a mitochondrial rR NA molecular clock rate of $0.14 \%$ transversion changes per million years, the average age of the trematomids is estimated at 3.4 million years (MY). If the age of the trematomids is approximately 3.4 MY, this group could have speciated during a period of deglaciation in Antarctica 2.5-4.8 million years ago. This era was marked by significant changes on the Antarctic shores, such as the opening of fjords, which might have provided a stimulus for speciation.

\section{INTRODUCTION}

Many fishes of the Perciform suborder Notothenioidei are endemic to the waters surrounding Antarctica (Andriashev, 1965, 1987). The notothenioids have radiated and possess a variety of unique characters distinguishing them from most other teleost fishes, such as antifreeze glycopeptides and the loss of hemoglobin in some species (Kock, 1992; Eastman, 1993; Miller, 1993). It has long been hypothesized that the Antarctic fauna evolved in situ as the continent cooled and froze (Regan, 1914; DeWitt, 1971; Anderson, 1990), and

\footnotetext{
${ }^{1}$ To whom correspondence should be addressed. E-mail: p.rit chie@auckland.ac.nz

2 Present address: Department of E cology, Massey University Private Bag 11-222, Palmerston North, New Zealand.
}

there is evidence that this may have occurred about 12-14 million years ago (MYA) (Eastman, 1993; Bargelloni et al., 1994).

There may have been a suite of factors which allowed the notothenioids, in particular, to evolve to such dominance in the Southern Oceans. Several authors have suggested that speciation within the group could have been the result of large-scale disruptions in the Antarctic ecosystem during the Miocene (Clarke, 1983). The isostatic pressure from the accumulation of ice during the early Miocene (25-15 MYA) left the continental shelf unusually small, deep, and lacking extensive topography (Andersen, 1991). It is likely that the presence of ice, which destroyed high coastal habitats and caused the depression of the continental shelf, resulted in the extinction of many other species. In addition, because the ice is anchored to the continent, riverine, estuarine, and intertidal zones were completely lost. Hence, any species that did not live in the deeper waters may not have survived these periods of extensive glaciation. The ecological void, freezing water temperatures, a circumpolar current impeding immigration, and dramatic seasonal oscillation in productivity acting in concert may have decreased competition by other fishes and hence have allowed notothenioids to diversify (see Clarke, 1983; Clarke and Crame, 1989; Eastman and Grande, 1989). There is evidence that the notothenioids, which lack a swim bladder, evolved from a benthic ancestor (Andersen, 1984; Balushkin, 1984).

In the complete absence of a fossil record this speciation scenario is difficult to test. Harwood (1991) suggested that a partial deglaciation around 2.5-4.8 MYA, and the resultant opening of shallow water habitats (including fjords), promoted diversification of various Antarctic biotas. The trematomids are high Antarctic fishes and might have radiated during the period of deglaciation 2.5-4.8 MYA in the mid-Pliocene. The new habitats and diverse biota resulting from this climate warming could have promoted speciation events. 
TABLE 1

The Subfamily Trematominae and the Outgroups Used in this Study (Following DeWitt et al., 1990)

Suborder Notothenioidei

Family Nototheniidae

Subfamily Eleginopinae Dissostichus mawsoni

Subfamily Nototheniinae Notothenia coriiceps Gobionotothen gibberifrons

Subfamily Trematominae

Pagothenia borchgrevinki

P. brachysoma ${ }^{b}$

Trematomus bernacchii

T. eulepidotus

$\mathrm{T}$. hansoni

$\mathrm{T}$. lepidorhinus

T. Ioennbergi

T. newnesi

T. nicolai

T. pennelii

T. scotti

T. tokarevi

T. vicarius ${ }^{b}$

a The second column is the habitat type for each species (from Eastman, 1993).

b Taxa not represented in this study.

\section{MATERIALS AND METHODS}

The trematomids comprise two genera, Trematomus (with 11 species) and Pagothenia (with 2 species), based on the classification in DeWitt et al. (1990) (Table 1). MtDNA sequences from the 125 and 165 ribosomal RNA (rRNA) genes were determined for 10 taxa from the subfamily Trematominae (Table 1). Three trematomid taxa were not represented in this study: Pagothenia brachysoma, Trematomus tokarevi, and T. vicarius. MtDNA sequences for taxa from the family Nototheniidae, Notothenia corii ceps, Gobionotothen gibberifrons, and Dissostichus mawsoni, have been published previously (Bargelloni et al., 1994) and were included in this study as outgroups. Specimens were collected from McMurdo Sound, Terra Nova Bay, and near the Antarctic Peninsula (Fig. 1) and either frozen in liquid nitrogen at $-20^{\circ} \mathrm{C}$ or preserved in $70 \%$ ethanol.

\section{DNA Methods}

Total genomic DNA was extracted from white muscle or liver tissue following Sambrook et al. (1989). Each tissue was dissolved in $500 \mu \mathrm{l}$ of extraction buffer $(0.01$ $M$ Tris- $\mathrm{HCl}, \mathrm{pH} 8.0,0.05 \mathrm{M} \mathrm{NaCl}, 0.01 \mathrm{M} \mathrm{EDTA}, 2 \%$ SDS) containing proteinase $\mathrm{K}$ and incubated at $55^{\circ} \mathrm{C}$ overnight. The digested tissue was purified by standard methods of phenol-chloroform extraction. Nucleic acids were then precipitated with 2.5 vol of $100 \%$ ethanol followed by a $70 \%$ ethanol wash. The precipatant

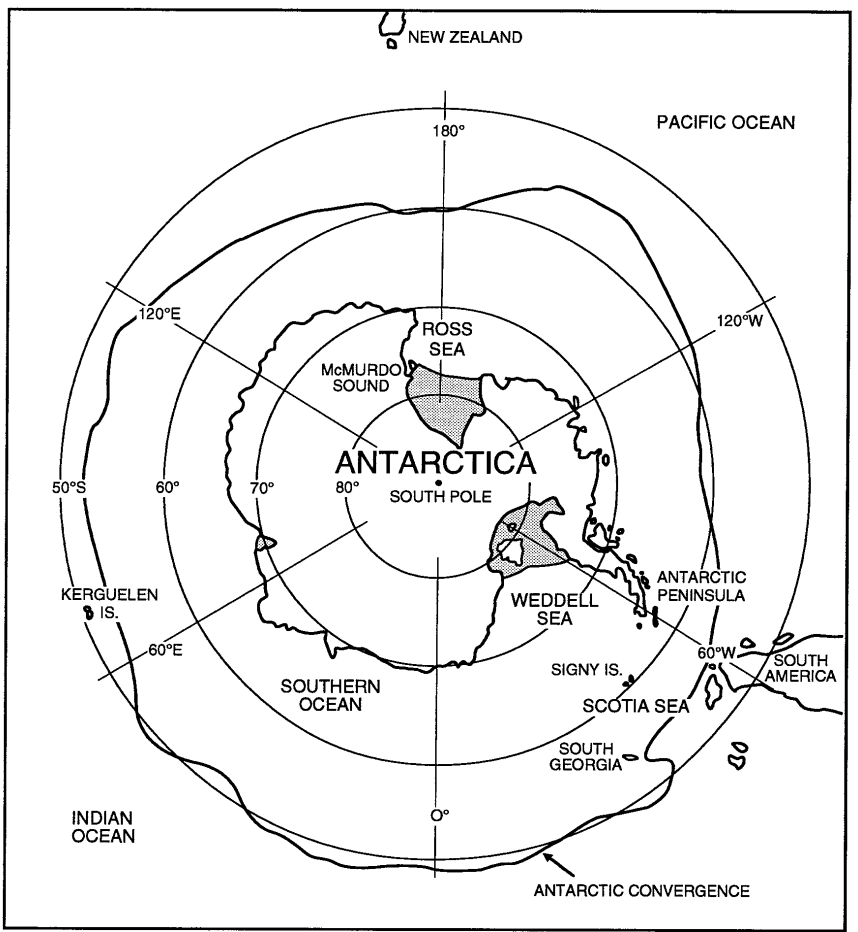

FIG. 1. Map of Antarctica, also showing the Antarctic Convergence, which delineates the Southern Ocean (redrawn from Macdonald et al., 1987). The gray areas indicate the permanent ice shelves in the Ross Sea and the Weddell Sea. Samples for this study were collected in McMurdo Sound and off the coast of the Antarctic Peninsula.

was pelleted in a microfuge, dried, and resuspended in $200 \mu \mathrm{l}$ of distilled $\mathrm{H}_{2} \mathrm{O}$. The polymerase chain reaction (PCR) (Saiki et al., 1988) was used to amplify two segments from the $12 S$ and $16 S$ rRNA genes using universal PCR primers: 12SA, 5'-AAAAAGCTTCAAACTGGG ATTAGATACCCCACTAT-3'; 12SB, 5'-TGACTGCAGA GGGTGACGGGGCGGTGTGT-3'; 16SA, 5'-CGCCTGT TTATCAAAACAT-3'; 16SB, 5'-CCGGTCTGAACTCAG ATCACGT-3' (Kocher et al., 1989; Palumbi et al., 1991). Double-stranded amplifications were performed in 50$\mu \mathrm{l}$ volumes containing $10 \mathrm{mM}$ Tris (pH 8.3), $100 \mathrm{mM}$ $\mathrm{KCl}, 2.5 \mathrm{mM} \mathrm{MgCl}_{2}, 1 \mathrm{mM}$ of each dNTP, $1 \mu \mathrm{M}$ of each primer, 10-1000 ng of genomic DNA, and 1 unit of Taq polymerase (Cetus Corp.). PCR was carried out in a Techethermal cycler at $92^{\circ} \mathrm{C} / 40 \mathrm{~s}, 52^{\circ} \mathrm{C} / 40 \mathrm{~s}$, and $72^{\circ} \mathrm{C} /$ $90 \mathrm{~s}$ for 35 cycles. Double-stranded PCR products were electrophoresed in $2 \%$ agarose (in 0.045 M Tris-borate, 0.001 M EDTA buffer), excised, and purified in spin columns (Costar: Spin-X), followed by phenol extraction and ethanol precipitation. Sequencing reactions were carried out in 20- $\mu$ l volumes using a DyeDeoxy terminator sequencing kit (Applied Biosystems). Cycle sequencing reactions were carried out in a Perkin-EImer thermal cycler at $96^{\circ} \mathrm{C} / 30 \mathrm{~s}, 50^{\circ} \mathrm{C} / 15 \mathrm{~s}$, and $65^{\circ} \mathrm{C} / 4 \mathrm{~min}$ for 25 cycles. Removal of excess DyeDeoxy terminators from the reaction mix was achieved by two phenol- 
chloroform extractions and an ethanol/NaOAc precipitation followed by a $80 \%$ ethanol wash. The precipitate was dried down in a concentrator (Savant Speedivac) and resuspended in $5 \mu \mathrm{l}$ of formamide/50 mM EDTA (pH 8.0). Samples were denatured at $90^{\circ} \mathrm{C}$, transferred to ice, immediately loaded on an Applied Biosystems 373A automated sequencer, and run following the instructions of the manufacturer. All templates were sequenced completely in both directions; $374 \mathrm{bp}$ of the $12 \mathrm{~S}$ gene and $544 \mathrm{bp}$ of the $16 \mathrm{~S}$ gene were determined. The orthologous DNA sequences were aligned with the Genetics Computer Group Sequence Analysis Software Package (version 7.3.1-UNIX, Wisconsin, 1993) on a Silicon Graphics 4D/30 workstation.

\section{Phylogenetic Analyses}

In this study parsimony, maximum-likelihood, and neighbor-joining methods were employed in the phylogenetic analysis; these have all been shown to be similar in accuracy (Hillis et al., 1994). Phylogenetic analyses were performed using maximum parsimony (MP) implemented in PAUP (Swofford, 1993), using the heuristic search procedure, with 100 random replicates. The robustness of the phylogeny was assessed with bootstrap analyses of 500 replicates (Felsenstein, 1985). Several different character weighting schemes were introduced since weighted parsimony can perform better (Hillis et al ., 1994). Analyses were done considering: (1) transitions and transversions equally; (2) a priori weighting of transversions and transitions (tv:ts) 2:1 according to the observed ratio between the ingroup and outgroup and within theingroup (ratio $=1.72$, Fig. 3); (3) additional tv:ts ratios of 3:1, 5:1 and 10:1; (4) transversions only. Also a successive-approximation approach to weighting of characters was performed according to their "cladistic reliability" (Farris, 1969; Williams and Fitch, 1989). Reweighting was based on both the mean rescaled and the consistency index of the most parsimonious tree found in parsimony analyses and a base weight of 1000 . Neighbor-joining analyses (NJ) (Saitou and Nei, 1987) were performed with MEGA (Kumar et al., 1993) and 500 bootstrap replicates were used to assess the confidence in the phylogenetic estimate. Different methods that accounted for multiple substitutions were used to estimate evolutionary distances: J ukes-Cantor (J ukes and Cantor, 1969), Kimura's two-parameter model (Kimura, 1980), and Tamura- Nei's method (Tamura, 1992). In addition, a maximum-likelihood (ML) analysis was conducted using PHYLIP: DNAML version 3.4.1. (Felsenstein, 1991) using default parameters (tv:ts ratio of 2 ).

\section{RESULTS}

\section{Sequence Analysis}

DNA sequences from this study are deposited in GenBank under Accession N os. U27520- U27529 and those of Bargelloni et al. (1994) in GenBank under Accession Nos. Z32702-Z32739 and Z32747-Z32748. Of the total 918 sites included in the analysis, 121 (13.2\%) are variable and 47 (5.1\%) are phylogenetically informative (Fig. 2). Across both the $12 \mathrm{~S}$ and $16 \mathrm{~S}$ data sets, no nucleotide composition bias was seen. On average (including outgroup taxa) the base composition was A, 28.3\%; T, 23.3\%; C, 24.4\%; and G, 24.1\%. More variation was observed in the $16 \mathrm{~S}$ data set (76 of the 544 bp were variable, $13.97 \%$ ) than in the $12 \mathrm{~S}$ data set (41 of the 374 bp were variable, 10.96\%) and only one indel was found (position 376-378 in the 16S data set). Overall, the level of variation was low; in no case do any species share haplotypes. The matrix of observed differences is shown in Table 2. The differences among members of the ingroup, when both transitions and transversions were considered, ranged from 5 to $36(0.5 \%-3.9 \%)$. When only transversions were considered, the substitutional differences ranged from as low as 0 to 18 (0$2.0 \%$ ). There is approximately $4.4 \%$ sequence divergence from the outgroup taxa N. coriiceps, G. gibberifrons, and D. mawsoni to the trematomids. The trematomids differed by as much as $15.2 \%$ sequence divergence from the most basal of the notothenioids, the bovichtids, Bovichthus variegatus (Bargelloni et al., 1994). Figure 3 shows the plot of transitions (ts) versus transversions (tv) for within the ingroup and between the ingroup and outgroup, with a best-fit line. The overall ratio of ts to tv, the slope of the best-fit line, is 1.72 (i.e., 1.72 transitions to every 1 transversion). Transitions have not reached saturation, either within the ingroup or between the ingroup and the outgroup (Fig. 3).

The sequences from this study were aligned with the complete sequences of the 12S rRNA of the cow (Gutell et al., 1985) and 16S rRNA of Xenopus (Gutell and F ox, 1988), for which the secondary structure of these genes is known. Thesereference sequences were used as models for the folding structure of the rRNAs and putative loops and stems were identified for the nototheniids. More variation, in terms of both substitutions and indels, is often observed in loops. A slight increasein variation is observed within the putative loops compared with the stem regions of the nototheniids (including the only recorded indel, position 376-378 in the 16S data set).

\section{Phylogenetic Analysis}

Both maximum parsimony (Fig. 4) and maximumlikelihood (Fig. 5) methods recovered trees with similar topologies, although the MP tree had two polytomies. Neighbor-joining (Fig. 6) showed agreement with these topologies apart from the phylogenetic position of $T$. newnesi, which was placed not as a sister group to the other trematomids (as in MP and ML) but as a deep clade within them. Both $T$. bernacchii and $T$. newnesi have longer branch lengths than any other ingroup 


T. hansoni
T. eulepiditous
T. nicolai
T. pennellii
T. lepidorhinus
T. loennbergi
T. bernacchii
T. newnesi
T. scotti
P. borchgrevinki
N. Coriiceps
G. gibberfrons
D. mawsoni

$16 \mathrm{~S}->$

TCGCAGCGTATCATGAAATAAGTGCAAGTCCAGTAATAAGTTTTGGACTGCGTTGCGAAAGTTTATAAAAAGATTGAA

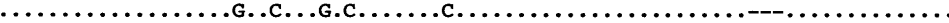

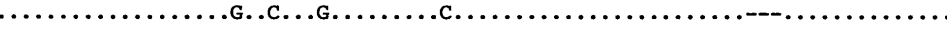

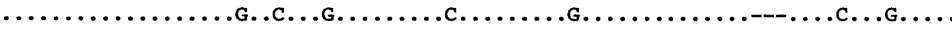

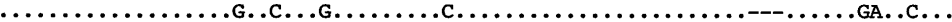

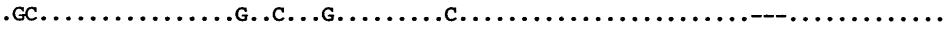

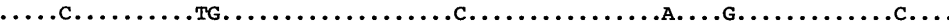
...GT....GCTGG.......C...G...........................T.T...TCT

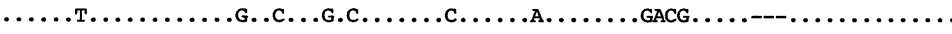

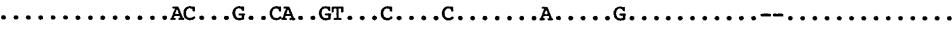
.................A.A.G.C.TC.G..C...CCCA..AC...A..A.G.A-_.........

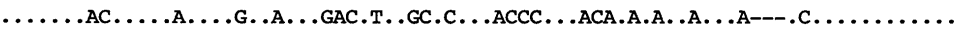
A. . . . . A. . . . . A. . . CGGAA. . GGACTTGAG. CC.GAGCCAA.GAC. .A.A. .AG . .A---GCG . . . . . . . . . 233356681111111111222222222222222222222222222233333333333333333334444444555555 136752950026337778001112223333334444455566667900112234455666677780035798000133 3967252397392381390267894578956912342805693490912357967863405349237467
12S $\rightarrow>$

TTAGTTAAACAAGCCGGCAATTAATAGATTCCAGTTACGTTGG ............................... ..............TT..CG......T..A.......A

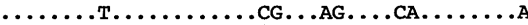
............................. ..............................CA

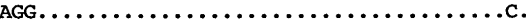
................................ ..............TTT.CG.AGA..............A ............................ ...A...C.AGCAATAATT..CG.A.AG....G..C.T.C..A -.ACC....GCAATAATT.A.GGC.A.A........T.C..A ...A......GCAATAATT.A.GGA.......A.A.C...CC.A 5555555555566677777777777888888888888889999 5666666789900433344456677002223344456890001 0013457291517134813454612016785757891702359

FIG. 2. The variable sites of the $12 \mathrm{~S}$ and $16 \mathrm{~S}$ mitochondrial rRNA sequences in this study. Positions in the complete sequences are given below.

TABLE 2

Distance Matrix for the Two Partial 12S and 16S rRNA Sequences

\begin{tabular}{|c|c|c|c|c|c|c|c|c|c|c|c|c|c|}
\hline & 1 & 2 & 3 & 4 & 5 & 6 & 7 & 8 & 9 & 10 & 11 & 12 & 13 \\
\hline $1 \mathrm{~T}$. hansoni & - & 1.2 & 1.3 & 1.5 & 1.5 & 1.5 & 1.2 & 3.0 & 2.6 & 1.9 & 4.8 & 5.0 & 6.1 \\
\hline 2 T. eulepidotus & $11 / 1$ & - & 0.5 & 1.2 & 0.5 & 0.5 & 2.4 & 2.4 & 1.6 & 1.3 & 4.2 & 4.6 & 5.9 \\
\hline 3 T. nicolai & $12 / 1$ & $5 / 0$ & - & 1.1 & 0.7 & 0.7 & 2.5 & 2.3 & 1.8 & 1.2 & 4.3 & 4.5 & 5.8 \\
\hline $4 \mathrm{~T}$. pennellii & $14 / 3$ & $11 / 4$ & $10 / 4$ & - & 1.3 & 1.3 & 2.7 & 2.7 & 2.4 & 1.6 & 4.6 & 5.1 & 6.2 \\
\hline 5 T. lepidorhinus & $14 / 1$ & $5 / 0$ & $6 / 0$ & $12 / 4$ & - & 0.7 & 2.7 & 2.5 & 2.0 & 1.4 & 4.7 & 4.9 & 6.2 \\
\hline 6 T. Ioennbergi & $14 / 4$ & $5 / 3$ & $6 / 3$ & $12 / 7$ & $6 / 3$ & - & 2.5 & 2.5 & 2.0 & 1.4 & 4.7 & 4.9 & 6.2 \\
\hline $7 \mathrm{~T}$. bernacchii & $11 / 6$ & $22 / 7$ & $23 / 7$ & $25 / 9$ & $25 / 7$ & $12 / 8$ & - & 3.9 & 3.7 & 3.1 & 5.9 & 6.2 & 7.3 \\
\hline $8 \mathrm{~T}$. newnesi & $27 / 12$ & $22 / 11$ & $21 / 11$ & $25 / 15$ & $23 / 11$ & $23 / 14$ & $36 / 18$ & - & 3.3 & 2.8 & 5.9 & 6.1 & 7.3 \\
\hline 9 T. scotti & $24 / 8$ & $15 / 7$ & $16 / 7$ & $22 / 11$ & $18 / 7$ & $18 / 10$ & $34 / 14$ & $30 / 15$ & - & 2.5 & 4.3 & 4.7 & 5.8 \\
\hline 10 P. borchgrevinki & $17 / 5$ & $12 / 4$ & $11 / 4$ & $15 / 8$ & $13 / 4$ & $13 / 7$ & 28/11 & $26 / 15$ & $23 / 11$ & - & 4.4 & 4.7 & 5.7 \\
\hline 11 N. coriiceps & $44 / 14$ & $38 / 13$ & $39 / 13$ & $42 / 17$ & $43 / 13$ & $43 / 16$ & $54 / 20$ & $54 / 22$ & $39 / 14$ & $40 / 15$ & - & 2.5 & 3.7 \\
\hline 12 G. gibberifrons & $46 / 11$ & $42 / 10$ & $41 / 10$ & $47 / 14$ & $45 / 10$ & $45 / 13$ & $57 / 17$ & $56 / 19$ & $43 / 15$ & $43 / 14$ & $23 / 11$ & - & 3.2 \\
\hline 13 D. mawsoni & $56 / 14$ & $54 / 13$ & $53 / 13$ & $57 / 17$ & $57 / 13$ & $57 / 16$ & $67 / 20$ & $67 / 22$ & $53 / 14$ & $52 / 17$ & $34 / 10$ & $29 / 7$ & - \\
\hline
\end{tabular}

Note Above the diagonal is the uncorrected percentage sequence difference between all pairs of taxa; bel ow the diagonal is the number of substitutions between all pairs of taxa and the number of substitutions when considering transversions only.

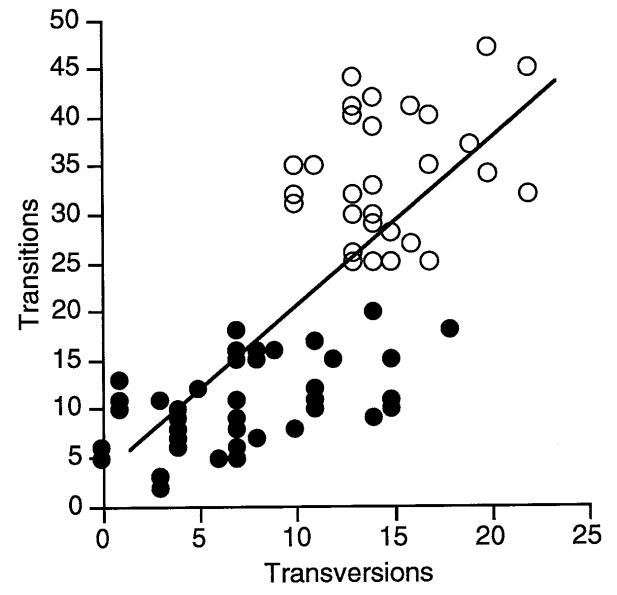

FIG. 3. A pairwise comparison of transitions versus transversions for the $12 \mathrm{~S}$ and $16 \mathrm{~S}$ rRNA sequences, encompassing the 10 trematomids and the 3 outgroup taxa. The open circles represent differences between ingroups and outgroup taxa and the closed circles represent differences within the ingroup taxa. The slope of the line is 1.72 , which was used to weight transversions more than transitions $\left(y=1.72 x+2.14 ; r^{2}=0.558\right)$. taxon. Different weighting schemes employed in the MP analysis recovered essentially the same topologies, apart from the analysis using transversions only, which had many polytomies. Furthermore, the successive-approximation approach to the weighting of characters recover ed a tree of the same topology as that of the unweighted MP tree in Fig. 4.

A measure of the phylogenetic signal within these data can be estimated by the skewness of treelength distributions, when generating 1000 random trees (Hillis and Huelsenbeck, 1992). This data set had a $g_{1}$ $=-1.822(\mathrm{P}<0.01)$, a highly significant skew, or deviation, from what would be expected from random phylogenetic noise (Fig. 7).

\section{DISCUSSION}

A phylogeny of the trematomids is useful for taxonomic purposes as well the investigation of evolutionary patterns and processes in the notothenioid radiation. Unfortunately, the morphological and karyological characters of this group have not proved to be 


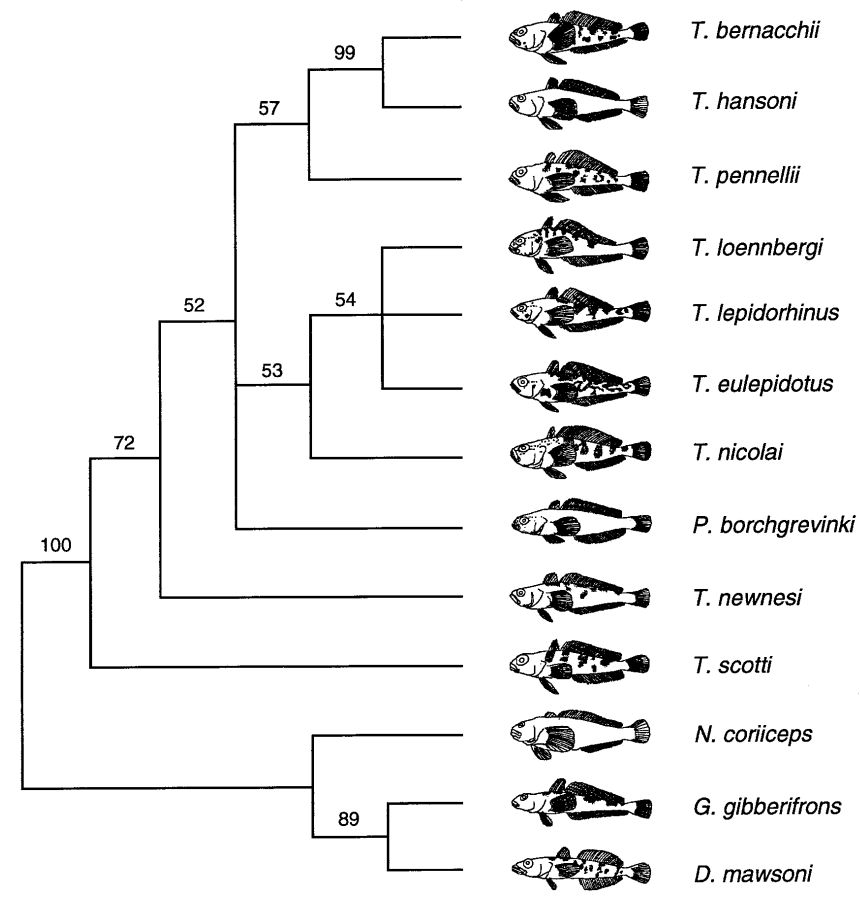

FIG. 4. The consensus parsimony tree with bootstrap values; based on unweighted analysis (100 replicates as implemented in PAUP 3.1.1., Swofford, 1993). A single MP tree has a length of 144 steps (consistency index $(\mathrm{Cl})=0.896$, rescaled $\mathrm{Cl}=0.754$ ). The numbers on the branches indicate the percentage of trees in the bootstrap analysis that shared that topology. These fishes have been redrawn from DeWitt et al. (1990).

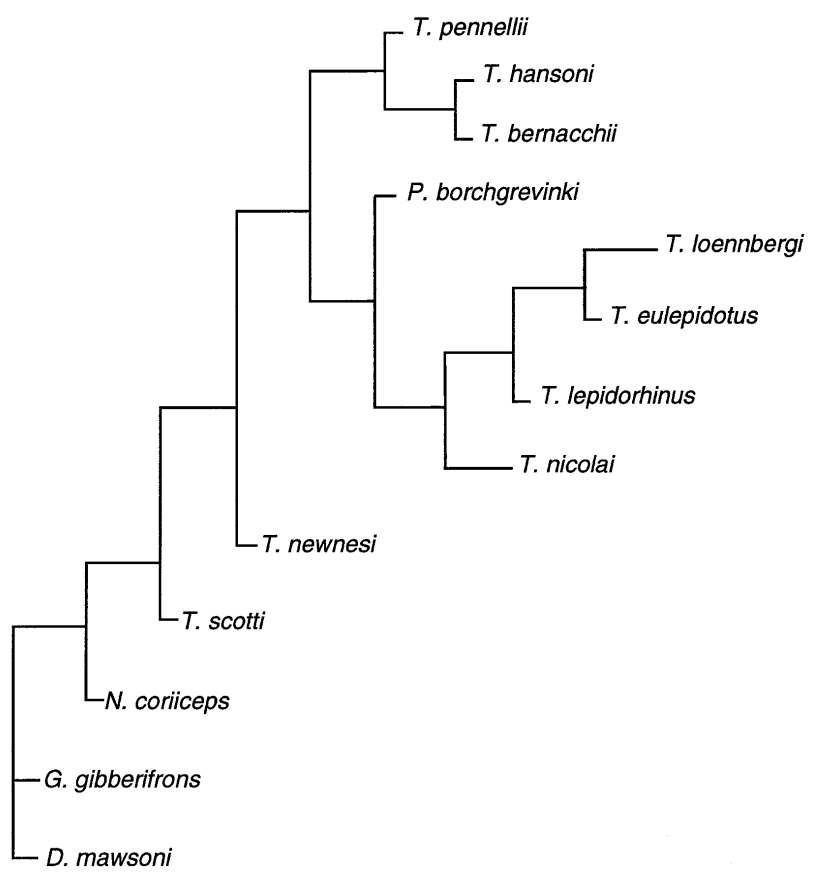

FIG. 5. Maximum-likelihood tree (as implemented in PHYLIP version 3.4.1., Felsenstein, 1991) using the default setting transversions/transition ratio of $1: 2$. fully reliable in resolving their interspecific relationships (Ekua, 1990; Morescalchi et al., 1992; Ritchie, 1993; Eastman, 1993; Klingenberg and Ekua, 1996). In addition, there is disagreement among several authors over the composition and taxonomic arrangement of the trematomids (Andersen and Hureau, 1979; Balushkin, 1982, 1984, 1992; Andersen, 1984; and Dewitt et al., 1990). MtDNA data can, in most cases, be extremely powerful for resolving species-level phylogenies (Meyer, 1993; Avise, 1994).

These mtDNA sequence data provide evidence that the trematomids are a recent radiation; there are low amounts of variation, particularly in the loops of the rRNA secondary structure. Bootstrap values varied between 100 and 41\%; the low values can be attributed to the small number of phylogenetically informative sites. Consequently, the number of transversions is small in several species and an analysis based only on transversions did not resol veevery clade. Themost conservative phylogeny for the trematomids is that found in Fig. 4, which is essentially the same as the ML tree (Fig. 5). The ML and $\mathrm{NJ}$ trees differ on the placement of $\mathrm{P}$. borchgrevinki, whereas the MP tree (Fig. 4) presents this taxon as an unresolved tricotomy. The following discussion will focus on Fig. 4, the MP tree.

\section{The Classification of Trematomid Fishes}

The genus Pagothenia was originally erected by Nichol s and Lamonte (1936) and contained a singlespecies P. brachysoma (a synonym to Notothenia antarctica). DeWitt (1962) suggested that T. borchgrevinki should also be moved into the genus Pagothenia and reported that $\mathrm{T}$. bernacchii and $\mathrm{T}$. hansoni showed certain similarities to Pagothenia. However, it was Andriashev and J akubowski (1971) who eventually classified $\mathrm{T}$. borchgrevinki in the genus Pagothenia. The genus Pagothenia, consisting of the two cyropelagic species (P. brachysoma and P. borchgrevinki), has been generally accepted (Andersen and Hureau, 1979; Andersen, 1984; Balushkin, 1984; DeWitt et al., 1990). The move of $\mathrm{T}$. hansoni, $\mathrm{T}$. bernacchii, and $\mathrm{T}$. tokarevi to Pagothenia by Andersen (1984) was controversial. The MP tree recovered from the two ribosomal genes surveyed here does not support Andersen's arrangement of the trematomids, as mentioned above. On the MP tree T. bernacchii, $T$. hansoni, and $\mathrm{T}$. pennellii are closely related, forming a monophyletic group, and P. borchgre vinki is a separate clade. Furthermore, T. hansoni and $\mathrm{T}$. bernacchii differ by a large amount of sequence divergence, 1.9 and $3.1 \%$, respectively, from $\mathrm{P}$. borchgre vinki.

Based on these mtDNA data, P. borchgrevinki is surely part of thetrematomid radiation but has evolved a unique cyropelagic existence. Many of the differences between Trematomus species and $\mathrm{P}$. borchgrevinki have been documented in Eastman and DeVries (1985). Further evidence for the close relationship of $\mathrm{P}$. borch- 


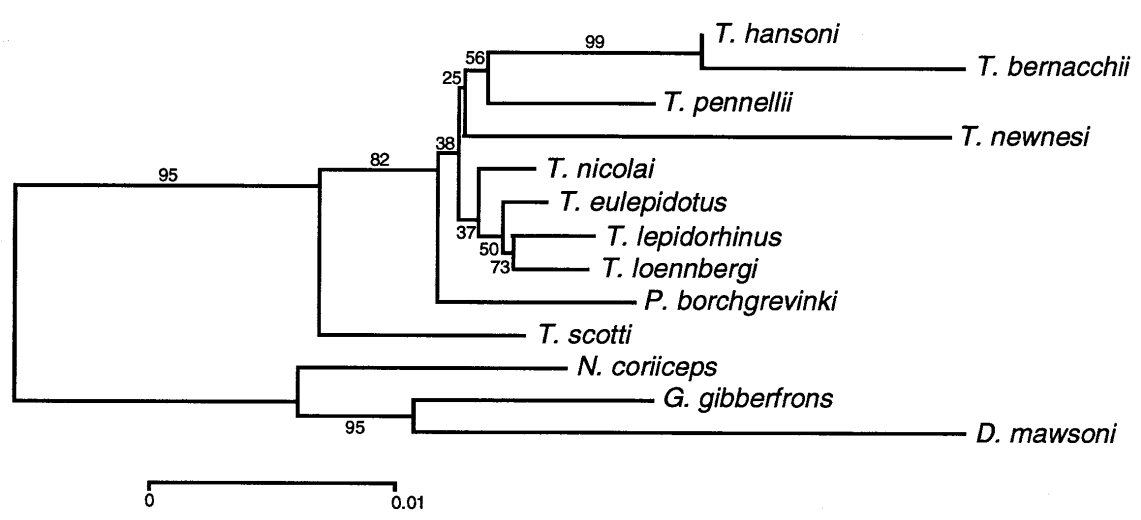

FIG. 6. Neighbor-joining tree based on distance measures that were corrected for multiple substitutions based on the Kimura twoparameter model. The scale shown indicates $1 \%$ sequence distance. The numbers on the branches indicate the percentage of trees in the bootstrap analysis (500 replicates) that shared that topology.

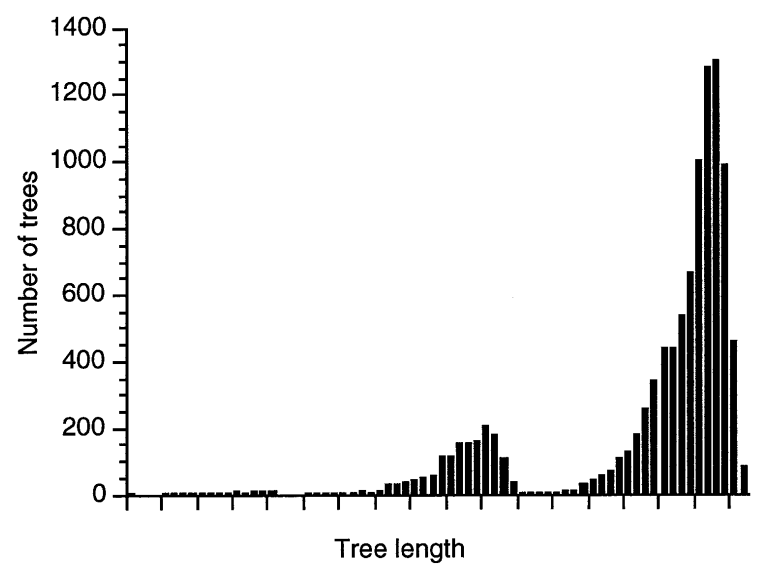

FIG. 7. The distribution of 1000 random trees from the $12 \mathrm{~S}$ and 16S rRNA sequences $\left(\mathrm{g}_{1}=-1.822, \mathrm{P}<0.01\right)$.

grevinki to other Trematomus species is the small genetic distance between these genera (based on 30 protein-coding loci, Roger's D $=0.483$ ), which falls within the range of the intrageneric distances $(D=$ 0.266- 0.508 ) of the surveyed trematomids (McDonald et al., 1992). This molecular phylogeny would suggest discarding the genus Pagothenia; this is beyond the scope of a single molecular data set especially in view of the morphological basis of this genus (Andriashev and J akubowski, 1971).

T. scotti does not appear as part of the main trematomid radiation (Figs. 4-6). This is a trematomid species with unusual opercular bones and a distinctive sexual dimorphism, which is unique among the notothenioids (DeWitt et al., 1990) and could be given separate generic status. Even though $\mathrm{T}$. scotti is most basal on these phylogenies, in terms of percentage sequence divergence $T$. scotti is not as distant as $T$. newnesi from all other trematomids (Table 2).

Balushkin (1982) moved Trematomus taxa into a new genus, Pseudotrematomus, reserving Trematomus for newnesi, the type specimen of the genus. This ge neric isolation of $T$. newnesi was based on the degree of ossification of the primary pectoral girdle, the size and position of the scapular foramen, the shape of the lower edge of the coracoid, and the degree of development of the postcoracoidial. Further evidence for the uniqueness of $T$. newnesi can be found in hemoglobin components. T. newnesi is the only notothenioid that possesses a second major hemoglobin type, $\mathrm{Hb} \mathrm{C}$ (di Prisco et al., 1991). Based on the position of T. newnesi in the present phylogeny, Balushkin's (1992) generic isolation of this species seems supported. However, a phylogenetic analysis of morphological data does not show T. newnesi as a sister taxon to the other trematomids but rather as a part of the radiation itself (Klingenberg and Ekua, 1996; Ritchie, 1993).

The Origin and Diversification of the

\section{Trematomid Radiation}

Various environmental conditions are supposed to be responsible for speciation events within lineages. Major climatic changes separated by several million years could account for many speciation events (Vrba, 1993). Because habitat limitations could have been important in the evolution of notothenioids, the opening of a coastal environment due to a period of deglaciation could have been the appropriate condition for speciation in high Antarctic fishes, such as the trematomids. Further, evidence of a speciation pulse in the trematomids at approximately the same time as the deglaciation should be expected. This information can be obtained from divergence dates if an accurate calibration of the notothenioid clock is available.

Since there is no fossil record for notothenioids, an absolute calibration of divergence times for molecular data is elusive. Recently studies contend that thermal habit, generation time, and metobolic rates are among the different factors influencing mutation rates in the mitochondrial genome (Martin and Palumbi, 1993; 
Rand, 1994). As noted in Bargelloni et al. (1994), the rate of the molecular clock may be significantly slower in the notothenioids than in other vertebrates since the body temperature of many notothenioids is below the freezing point. A further complication is that notothenioids may exhibit metabolic cold adaptation (MCA), although evidence for this is controversial (Macdonald et al., 1987). MCA is the elevation of metabolic rate to a higher level than predicted when extrapolated from temperate fish at subzero temperatures. As more physiological and molecular data accumulate for the trematomids a more accurate estimate of the rate of molecular evolution can be obtained.

The estimated rates of change for transversions $(0.14 \% / \mathrm{MY})$ in rRNA genes were found to be identical in endotherms (Kraus and Miyamoto, 1991) and ectotherms (Caconne et al., 1994). Since the average percentage sequencedivergence (using transversions only) within the trematomid radiation is $0.482 \%$ (excluding $\mathrm{T}$. newnesi and $\mathrm{T}$. scotti) the average age of the radiation would beapproximately 3.4 MY. This estimate correlates with the period of partial deglaciation between 2.5 and 4.8 MYA, postulated by Harwood (1991) as a stimulus for speciation on the coasts of Antarctica. Although this calibration is putative, further studies of the rate of molecular change of the trematomid mitochondrial genome are necessary.

The trematomids occupy a variety of ecological niches in Antarctica, supposedly all having originated from a benthic form. Table 1 shows the ecological type assigned to each trematomid species (based on Eastman, 1993). The distributions of the benthic forms on the phylogeny, in particular two outgroup species and the most basal ingroup T. scotti, provide further evidence that this is the primitive condition. The cyropelagic existence of $\mathrm{P}$. borchgrevinki and pelagic habits of $\mathrm{T}$. newnesi are uniqueon the phylogeny. Moreinteresting, the benthic forms, $T$. bernacchii, $T$. hansoni, and $T$. pennellii, are monophyletic, as are the epibenthic forms T. loennbergi, T. lepidorhinus, and T. eulepidotus. There are limited amounts of ecological diversification among closely related species. During the period of deglaciation (2.5-4.8 MYA) there could have been much more ecological diversity. The fact that these benthic and epibenthic species are indeed monophyletic and share many characters means either a recent radiation or a slow-evolving species rather than sets of convergent taxa.

\section{ACKNOWLEDGMENTS}

Thanks to A. L. DeVries, K.-H. Kock, C. Zimmermann, and G. di Prisco for assistance with specimens for this study.J .A.M. and P.A.R. appreciate the continued support and hospitality of all those at Scott Base (New Zealand), Terra Nova Station (Italy), and McMurdo Station (United States). Thanks to Kristine Boxer and Vivian Ward for their technical assistance and also to Alexa Bely and the four anonymous reviewers for comments on the manuscript. This work was sup- ported as part of the New Zealand Antarctic Research Programme, by grants to D.M.L. and J .A.M. from the Auckland University Research Committee, by grants (BSR-9119867 and BSR-9107838) from the U.S. National Science F oundation to A.M., and from the Programma Nazionale di Richerhe in Antartide to L.B.

\section{REFERENCES}

Andersen, J . B. (1991). The Antarctic continental shelf: Results from marine geological and geophysical investigations. In "The Geology of Antarctica" (R. J . Tingey, Ed.), pp. 285-334, Oxford Univ. Press, Oxford.

Andersen, N. C. (1984). Genera and subfamilies of the family Nototheniidae (Pisces, Perciformes) from the Antarctic and Subantarctic. Steenstrupia 10: 1-34.

Andersen, N. C., and Hureau, J.-C. (1979). Proposition pour une nouvelle classification des Nototheniinae (Pisces, Perciforms, Nototheniidae). Cybium 3(6): 47-53.

Anderson, M. E. (1990). The origin and evolution of the Antarctic ichthyofauna. In "Fishes of the Southern Ocean" (O. Gon and P. C. Heemstra, Eds.), pp. 28-33, J . L. B. Smith I nstitute of I chthyology, Grahamstown, South Africa.

Andriashev, A. P. (1965). A general review of the Antarctic fish fauna. In "Biogeography and Ecology in Antarctica" (P. van Oye and J . van Mieghem, Eds.), pp. 491-550, Monogr. Biol., Vol. XV. J unk, The Hague, Netherlands.

Andriashev, A. P. (1987). A general review of the Antarctic bottom fish fauna. In "Fifth Congress of European I chthyologist Proceedings, Stockholm, 1985" (S. O. Kullander and B. Fernholm, Eds.), pp. 357-372.

Andriashev, A. P., and J akubowski, M. (1971). Morphological grounds for generic separation of the Antarctic broadhead fishes (Trematomus bochgrevinki Boulenger and T. brachysoma Pappenheim) and a new species of the genus Pagothenia Nichols et LaMonte (Nototheniidae). Zool. Zh. 50: 1041- 1055 (in Russian).

Avise, J . (1994). "Molecular Markers, Natural History and Evolution," Chapman and Hall, New York.

Balushkin, A. V. (1982). Classification of trematominae fishes of the Antarctic. In "Biology of Shelf Zones of the World's Oceans," pp. 9-10, 2. DVNTs SSSR, Vladivostok (in Russian).

Balushkin, A. V. (1984). "Morphological bases of the systematics and phylogeny of the nototheniid fishes," Acad. Sci. USSR, Zool. Inst. Leningrad.

Balushkin, A. V. (1992). Classification, phylogenetic relationships, and the origins of the families of the Suborder N otothenioidei (Perciformes). J . Ichthyol. 32(3): 90-110.

Bargelloni, L., Ritchie, P. A., Patarnello, T., Battaglia, B., Lambert, D. M., and Meyer, A. (1994). Molecular evolution at subzero temperatures: Mitochondrial and nuclear phylogenies of fishes from Antarctica (suborder Notothenioidei), and the evolution of antifreeze glycopeptides. Mol. Biol. Evol. 11: 854-863.

Caconne, A., Milinkovitch, M. C., Sborboni, V., and Powell, J. R. (1994). Molecular biogeography: Using the Corsica-Sardinia microplate disjunction to calibrate mitochondrial rDNA evolutionary rates in mountain newts (Euproctus). J . Evol. Biol. 7: 227-245.

Clarke, A. (1983). Life in cold water: The physiological ecology of polar marine ectotherms. Oceanogr. Mar. Biol. Ann. Rev. 21: 341453.

Clarke, A., and Crame, J. A. (1989). The origins of the Southern Oceans marine fauna. In "Origins and Evolution of the Antarctic Biota" (J . A. Crame, Ed.), pp. 253-268, The Geological Society, London.

DeWitt, H. H. (1962). A new Antarctic nototheniid fishes with notes on two recently described nototheniiforms. Copeia 4: 819-833. 
DeWitt, H. H. (1971). Coastal and deep-water benthic fishes of the Antarctic. Antarct. Map Folio Series 15: 1-10.

DeWitt, H. H., Heemstra, P. C., and Gon, O. (1990). Nototheniidae. In "Fishes of the Southern Ocean" (O. Gon and P. C. Heemstra, Eds.), pp. 279-331, J . L. B. Smith Institute of Ichthyology, Grahamstown, South Africa.

di Prisco, G., D'Avino, R., Caruso, C., Tamburini, M., Camardella, L., Rutigliano, B., Carratore, V., and Romano, M. (1991). The biochemistry of oxygen transport in red-blooded Antarctic fish. In "Biology of Antarctic Fish" (G. di Prisco, B. Maresca, and B. Tota, Eds.), pp. 262-281, Springer-Verlag, Berlin.

Eastman, J . T. (1993). “Antarctic Fish Biology," Academic Press, San Diego.

Eastman, J . T., and DeVries, A. L. (1985). Adaptations for cryopelagic life in the Antarctic notothenioid fish Pagothenia borchgrevinki. Polar Biol. 4: 45- 52.

Eastman, J . T., and Grande, L. (1989). Evolution of the Antarctic fish fauna with emphasis on the recent nototheniids. In "Origins and Evolution of the Antarctic Biota" (J . A. Crame, Ed.), pp. 241-252, Geogr. Soc. Special Publ. No. 47.

Ekua, W. (1990). Demersal fish fauna of the Weddell Sea, Antarctica. Antarct. Sci. 2: 129-137.

Farris, J . S. (1969). A successive approximations approach to character weighting. Syst. Zool. 18: 374- 385.

Felsenstein, J . (1985). Confidencelimits on phylogenies: An approach using the bootstrap. Evolution 39: 783-791.

Felsenstein, J . (1991). PHYLIP version 3.4.1., University of Washington, Seattle.

Gutell, R. R., and Fox, G. E. (1988). A compilation of large subunit RNA sequences presented in a structural format. Nucleic Acids Res. 16(suppl.): r175-r269.

Gutell, R. R., Weiser, R., Woese, C. R., and Noller, H. F. (1985). Comparative anatomy of S-like ribosomal RNA. Prog. Nucleic Acid Res. Mol. Biol. 32: 155-216.

Harwood, D. M. (1991). Cenozoic diatom biogeography in the southern high latitudes: I nferred biogeography barriers and progressive endemism. In "Geological Evolution in Antarctica" (M. R. A. Thompson, J . A. Crame, and J . W. Thompson, Eds.), pp. 667-673, Cambridge Univ. Press, Cambridge.

Hillis, D. M., and Huelsenbeck, J . P. (1992). Signal, noise, and reliability in molecular phylogenetic analyses. J . Hered. 83: 189- 195.

Hillis, D. M., Huelsenbeck, J . P., and Cunningham, C. W. (1994). Application and accuracy of molecular phylogenies. Science 264: 671677.

J ukes, T. H., and Cantor, C. R. (1969). Evolution of protein molecules. In "Mammalian Protein Metabolism" (H. N. Munro, Ed.), pp. 21132. Academic Press, New York.

Kimura, M. (1980). A simple method for estimating evolutionary rate of base substitutions through comparative studies of nucleotidesequences. J . Mol. Evol. 16: 111-120.

Klingenberg, C. P., and Ekua, W. (1996). A combined morphometric and phylogenetic analysis of an ecomorphological trend: Pelagization in Antarctic fishes (Perciformes: Nototheniidae), Biol. J . Linn. Soc. (in press).

Kocher, T. D., Thomas, W. K., Meyer, A., Edwards, S. V., Pääbo, S., Villablanca, F. X., and Wilson, A. C. (1989). Dynamics of mitochondrial DNA evolution in animals: Amplification and sequencing with conserved primers. Proc. Natl. Acad. Sci. USA 86: 61966200.

Kock, K.-H. (1992). "Antarctic Fish and Fisheries," Cambridge Univ. Press, Cambridge.
Kraus, F., and Miyamoto, M. M. (1991). Rapid cladogenesis among the pecoran ruminants: Evidence from mitochondrial DNA sequences. Syst. Zool. 40(2): 117-130.

Kumar, S., Tamura, K., and Nei, M. (1993). “Molecular Evolutionary Genetics Analysis MEGA," ver. 1.0, The Pennsylvania State University, University Park, PA.

Macdonald, J . A., Montgomery, J . C., and Wells, R. M. G. (1987). Comparative physiology of Antarctic fishes. Adv. Mar. Biol. 24: 321-341.

Martin, A. P., and Palumbi, S. R. (1993). Body size, metabolic rate, generation time, and the molecular clock. Proc. Natl. Acad. Sci. USA 90: 4087-4091.

McDonald, M. A., Smith, M. H., Smith, M. W., Novak, J . M., J ohns, P. E., and DeVries, A. L. (1992). Biochemical systematics of notothenioid fishes from Antarctica. Biochem. Syst. E col . 20: 233-241.

Meyer, A. (1993). Evolution of mitochondrial DNA in fishes. In "Biochemistry and Molecular Biology of Fishes" (P. W. Mochachka and T. P. Mommsen, Eds.), Vol. 2, pp. 1-38, Elsevier, Amsterdam/New York.

Miller, R. G. (1993). "A History and Atlas of theFishes of the Antarctic Oceans," F oresta Institute, Nevada.

Morescalchi, A., Pisano, E., Stanyon, R., and Morescalchi, M. A. (1992). Cytotaxonomy of Antarctic teleosts of the Pagothenia/ Trematomus complex (Nototheniidae, Perciformes). Polar Biol . 12: 553- 558.

Nichols, J . T., and Lamont, F. R. (1936). Pagothenia, a new Antarctic fish. Am. Mus. Nov. 839: 1-4.

Palumbi, S. R., Martin, A., Romano, S., McMillan, W. O., Stice, L., and Grabowski, G. (1991). “The Simple Fool's Guide to PCR," Univ. of Hawaii Press, Honolulu.

Rand, D. M. (1994). Thermal habit, metabolic rate, and evolution of mitochondrial DNA. Trends Ecol. Evol. 9(4): 125-131.

Regan, C. T. (1914). "Fishes of the British Antarctic Expeditions (Terra Nova) Zoology Reports 1910," Vertebrata Vol 1, pp. 1-54, British Museum of Natural History, London.

Ritchie, P. (1993). "Molecular and Morphological Phylogenetics of Antarctic Fishes," M. Sc. thesis, University of Auckland, New Zealand.

Saiki, R. K., Gelfand, D. H., Stoffel, S., Scharf, S., Higuchi, R., Horn, R., Mullis, K. B., and Erlich, H. A. (1988). Primer-directed enzymatic amplification of DNA with a thermostable DNA-polymerase. Science 239: 487-491.

Saitou, H., and Nei, M. (1987). The neighbor-joining method: A new method for reconstructing phylogenetic trees. Mol. Biol. Evol. 4: 406- 425.

Sambrook, J ., Fritsch, E. F., and Maniatis, T. (1989). "Molecular Cloning: A Laboratory Manual," Cold Spring Harbor Lab. Press, NY.

Swofford, D. L. (1993). "Phylogenetic Analysis Using Parsimony (PAUP)," version 3.1.1., Illinois Natural History Survey, Champaign.

Tamura, K. (1992). Estimation of the number of nucleotide substitutions when there are strong transition-transversion and $\mathrm{G}+\mathrm{C}$ content biases. Mol. Biol. Evol. 9: 678-687.

Vrba, E. S. (1993). Mammal evolution in the African Neogene and a new look at the great American interchange. In "Biological Relationships between Africa and South America" (P. Goldblatt, Ed.), pp. 393-432, Yale University.

Williams, P. L., and Fitch, W. M. (1989). Finding the minimal change in a given tree. In "The Hierarchy of Life" (B. Fernholm, K. Bremer, and H. J örnfall, Eds.), pp. 453-470, Elsevier, Amsterdam. 